\title{
Deproteinated potato wastewater as a low-cost nitrogen substrate for very high yeast biomass quantities: starting point for scaled-up applications
}

\author{
Iwona Gientka ${ }^{1}$ (D) · Marta Duda ${ }^{1} \cdot$ Anna Bzducha-Wróbel ${ }^{1} \cdot$ Stanisław Błażejak $^{1}$
}

Received: 1 October 2018 / Revised: 27 December 2018 / Accepted: 3 January 2019 / Published online: 18 January 2019

(c) The Author(s) 2019

\begin{abstract}
The aim of this research was to investigate the influence of deproteinated potato wastewater (DPW) supplemented by different initial concentrations of glucose on biomass yield, especially lipids biosynthesis and fatty acids composition. DPW is a low-cost source of nitrogen and other biogenic elements. It allowed for an efficient yeast cells growth and a very high biomass yield of Rhodotorula glutinis var. rubescens LOCKR13. A short time of incubation leads to a biomass rich in protein, which can be a source of single-cell protein. The strain was able to accumulate $46 \%$ cell dry weight (CDW) of lipids in control medium and only $18 \%$ when DPW medium were used. The maximum volumetric lipids efficiency in the DPW medium was $6.14 \mathrm{~g} \mathrm{~L}^{-1}$. Oleic (41.0-51.5\%), palmitic (15.3-17.8\%), and stearic acids (5.8-7.5\%) dominated the entire pool of fatty acids. Theoretical calculations indicated a possibility to use the methylated esters of lipids from R. glutinis var. rubescens yeast as a biodiesel.
\end{abstract}

Keywords Rhodotorula $\cdot$ Deproteinated potato wastewater $\cdot$ Lipids biosynthesis $\cdot$ Single-cell oils $\cdot$ Biodiesel

\section{Introduction}

Research on biotechnological waste management involves many aspects, from genetic modification of strains to their resistance to toxic substances in waste, to proposing new technical solutions in bioreactors to reduce energy expenditure. Three types of organic wastes namely; potato juice, wastewater, and pulp are formed after the production of potato starch. Potato wastewater is the diluted potato juice produced during starch milk refining. About $6 \mathrm{~m}^{3}$ of potato wastewater is produced during the processing of 10 tons of potatoes [7]. To reduce the burden on potato wastewater, the starch processing plants perform the process of deproteinization by applying thermal-acid coagulation to remove proteins, which is then used in the production of animal feed [23]. After the deproteinization stage, potato wastewater is still characterized by high values of chemical oxygen

Iwona Gientka

iwona_gientka@sggw.pl

1 Department of Biotechnology, Microbiology and Food Evaluation, Faculty of Food Science, Warsaw University of Life Sciences-SGGW, Nowoursynowska Str. 159c, 02-776 Warsaw, Poland demand (COD) and biochemical oxygen demand $\left(\mathrm{BOD}_{5}\right)$ and can still cause serious environmental pollution when left untreated. Microorganisms utilizing food industry wastes are capable of biosynthesizing many valuable metabolites. Among them the yeast biomass can be a source of microbial proteins (single-cell protein), lipids (single-cell oil) and others useful in industries.

The yeast $R$. glutinis belongs to the group of oleaginous microorganisms, which are defined as microorganisms capable of producing and accumulating more than $20 \%$ of lipids in dry cellular substance [30]. The red yeast $R$. glutinis is a very efficient oleaginous yeast, that can accumulate up to $60 \%$ of its cell dry weight (CDW) in the form of lipids [31]. In addition, the fatty acid profile of the lipids yielded by the red yeast is comparable with that of the vegetable oils allowing for biodiesel production. Moreover, the former is comparatively unproblematic to handle, it being nontoxic and easy to grow and harvest. Furthermore, $R$. glutinis is also able to produce certain carotenoids, namely, $\beta$-carotene, torularhodin, and torulene [16].

Lipids may be accumulated via two pathways: de novo (from acetyl-CoA and malonyl-CoA molecules) and ex novo, with carbohydrates [27] and hydrophobic compounds [3] serving as substrates. Single-cell oils (SCO) can be used for 
a nutritional and/or energy purposes. The production of such oils for nutritional purposes is economically justified, only if it is an alternative to expensive and limited vegetable or animal oils. Currently, microbial producers of docosahexaenoic acid (DHA) and eicosapentaenoic acid (EPA) are needed [35]. SCO can also be used as a raw material for the extraction of valuable individual fatty acids such as purified palmitoleic. It may be a therapeutic approach in helping maintain lipid levels within a healthy range as well as improve inflammatory markers in patients with mild dyslipidemia and inflammation [4]. In contrast, SCO for biodiesel should comply with the guidelines described in EU or US standards defining good fuel parameters. Values of microbial biodiesel parameters are determined by the fatty acids composition of oils extracted from the biomass.

Until now, research on the biosynthesis of lipids by the yeast $R$. glutinis based on the valorization of liquid waste were focused on wastewater after the production of sodium glutamate [37], fruit juice processing [33], distillery wastewater obtained from the production of tequila [12], waste formed after the production of cellulose and hemicellulose (LCB lignocellulosic biomass hydrolysate) [38], undetoxified corncob hydrolysate [20], pulp and paper wastewater [1], and the loquat (Eriobotrya japonica L.) kernel extract [26].

The content of lipids in yeast biomass and its characteristics depend on many factors, including the composition of the medium. The aim of this study was to investigate the influence of glucose supplementation in deproteinated potato wastewater on biomass production, the lipids biosynthesis and the fatty acids composition.

\section{Results}

\section{Characteristics of DPW}

The chemical parameters of sterilized potato wastewater obtained from the process line after the deproteinization stage are shown in Table 1 . The dry matter content in the DPW was found to be $3.3 \%$ and the amount of reducing sugars was found to be $0.44 \%$. The average nitrogen level was found to be more than $1.6 \mathrm{~g} \mathrm{~L}^{-1}$, so the protein content calculated based on it was found to be $10 \mathrm{~g} \mathrm{~L}^{-1}$, and the protein concentration using the Lowry method was $3.3 \mathrm{~g} \mathrm{~L}^{-1}$.

\section{Biomass production and its composition}

In a medium containing peptone and yeast extract, the maximum yield of the biomass was more than $21 \mathrm{~g} \mathrm{~L}^{-1}$, and it was determined after culturing with $15 \%$ glucose (Table 2). The use of DPW has allowed to increase the biomass yield significantly and its maximum value was higher
Table 1 Chemical characteristic of deproteinated potato wastewater

\begin{tabular}{lc}
\hline Parameter & Value and unit \\
\hline Dry substance & $33.26 \pm 0.43 \mathrm{~g}_{\text {d.w. }} \mathrm{L}^{-1}$ \\
Sugars (directly reducing) & $4.40 \pm 0.03 \mathrm{~g} \mathrm{~L}^{-1}$ \\
Nitrogen & $1.62 \pm 0.06 \mathrm{~g} \mathrm{~L}^{-1}$ \\
Potassium & $4.14 \pm 0.32 \mathrm{~g} \mathrm{~L}^{-1}$ \\
Phosphorus & $0.33 \pm 0.02 \mathrm{~g} \mathrm{~L}^{-1}$ \\
Magnesium & $0.24 \pm 0.03 \mathrm{~g} \mathrm{~L}^{-1}$ \\
Calcium & $0.10 \pm 0.01 \mathrm{~g} \mathrm{~L}^{-1}$ \\
Sodium & $0.061 \pm 0.005 \mathrm{~g} \mathrm{~L}^{-1}$ \\
Manganese & $0.002 \pm 0.0002 \mathrm{~g} \mathrm{~L}^{-1}$ \\
\hline
\end{tabular}

than $39 \mathrm{~g} \mathrm{~L}^{-1}$. The yield of the biomass obtained after DPW culture was up to $86 \%$ higher; thus, it is important to recognize that the components of the DPW medium significantly promoted yeast cell growth.

The highest content of lipids ( $>46 \% \mathrm{CDW}$ ) was observed after culturing in YP containing $20 \%$ glucose (Table 2). After cultivating in the potato wastewater, the maximum lipids content was higher than $18 \% \mathrm{CDW}$, which was recorded in the medium at an initial content of $20 \%$ glucose. The lipids content in the biomass was even more than five times (more) higher after culturing in YP than in DPW, but when compared with volumetric lipids efficiency, the difference was only $22 \%$. Regardless of the type of the substrate, the increase in the initial concentration of the carbon source lead to an increase in the lipid content of the biomass, mainly at the expense of intracellular sugars. But, the proportion of proteins in the biomass obtained after YP culture did not change significantly. As the initial glucose concentration increased in the DPW medium, fat content increased, which was followed by a decrease in the content of intracellular sugars and proteins. The type of the substrate influenced significant differences in the coefficients, indicating the amount of lipids, sugars, and proteins, from $1 \mathrm{~g}$ of consumed glucose $\left(Y_{\mathrm{L} / \mathrm{S}}, Y_{\mathrm{S} / \mathrm{S}}\right.$, and $\left.Y_{\mathrm{P} / \mathrm{S}}\right)$. Lipids/glucose and sugars/glucose yield coefficient for the culture conducted in YP medium had similar values. Glucose utilization during the DPW culturing was targeted at the synthesis of sugars in the biomass. This is indicated by the $Y_{\mathrm{S} / \mathrm{S}}$ values that were up to ten times that of the $Y_{\mathrm{L} / \mathrm{S}}$. These differences diminished with the increasing initial glucose concentration. During the yeast cultivation was observed the spontaneous alkalization of DPW medium (Table 2).

The significant changes in the content of main intracellular components of the yeast biomass were observed during culturing. Between 72 and $96 \mathrm{~h}$ of the culture in YP medium (Fig. 1a), the content of lipids in the biomass was significantly increased and the sugar content was decreased, which did not depend on the initial concentration of glucose. At the same time, an inverse relationship was observed in 


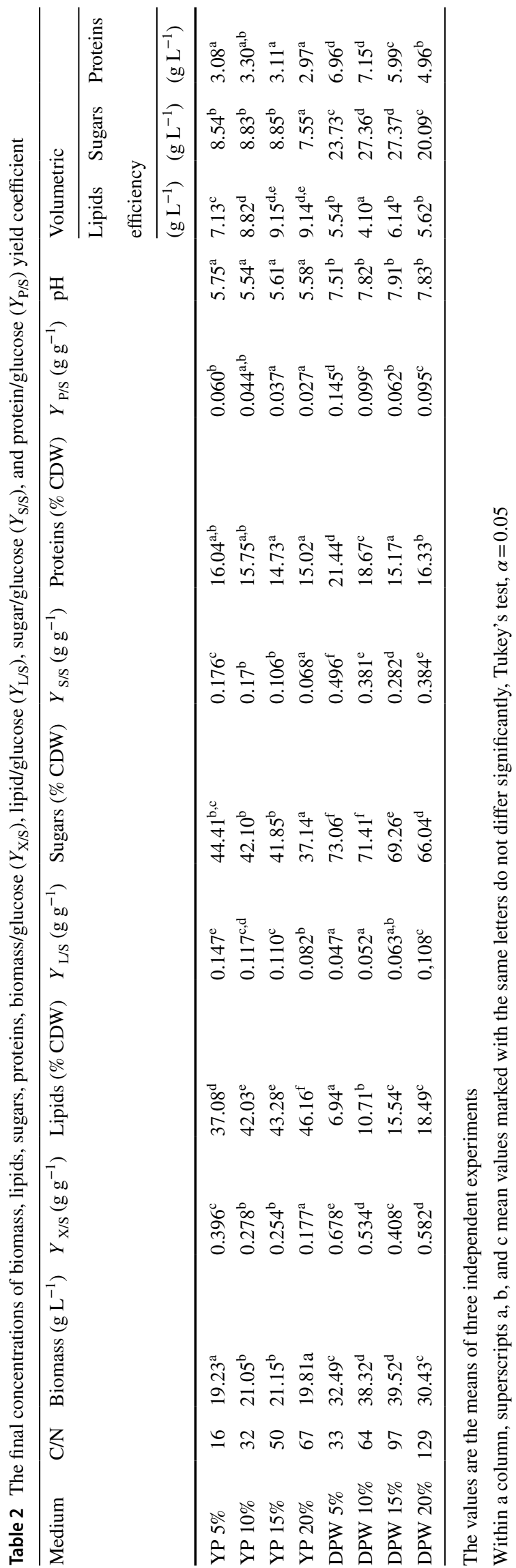

(a)

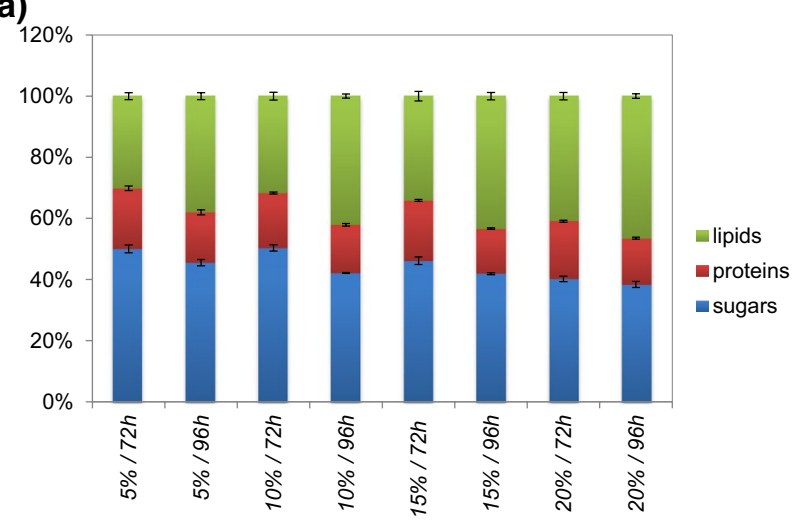

(b)

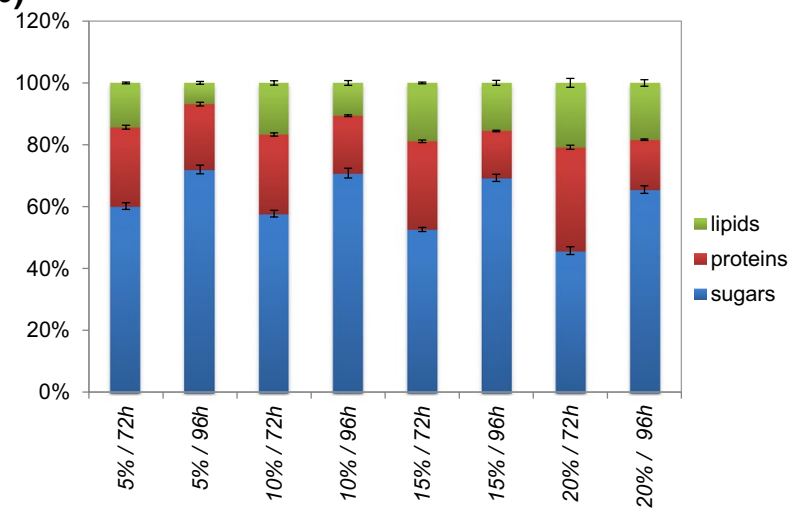

Fig. 1 Total content of the main cellular metabolites after culturing Rhodotorula glutinis var rubescens in YP (a) and DPW media (b). Values represent the average of triplicate experiments \pm standard deviations

the DPW medium (Fig. 1b). After $72 \mathrm{~h}$, the biomass was characterized by a lesser proportion of lipids, which was inversely proportionate with the glucose in the medium. The proteins content decreased and the greatest change in their concentration was observed in the biomass after culturing $20 \%$ glucose medium. The final content of the individual intracellular metabolites indicates a better lipid synthesis capability, when the nitrogen source and other compounds are peptone and yeast extract than DPW.

\section{Kinetic of growth and lipids production}

The course of growth curves and the rate of carbon and nitrogen sources and consumption depended on their type and initial concentration. In a YP 5\% medium, rapid glucose and nitrogen consumption were up to $48 \mathrm{~h}$ and the cells reached a stationary phase (Fig. 2a). At this point, the biomass was characterized by the highest content of sugars. Then, lipids biosynthesis followed the decline of sugars and proteins. For using glucose at a concentration of $20 \%$ (Fig. 2b), after $48 \mathrm{~h}$ biomass yield continued to increase significantly. Significant increase in initial 


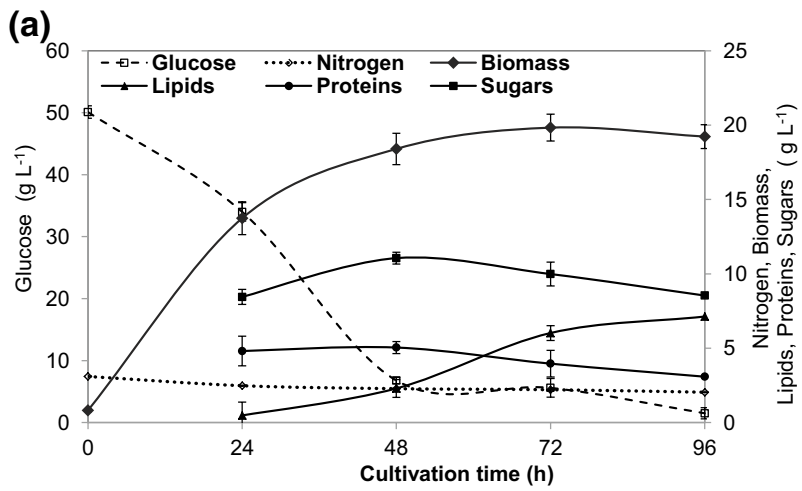

(b)

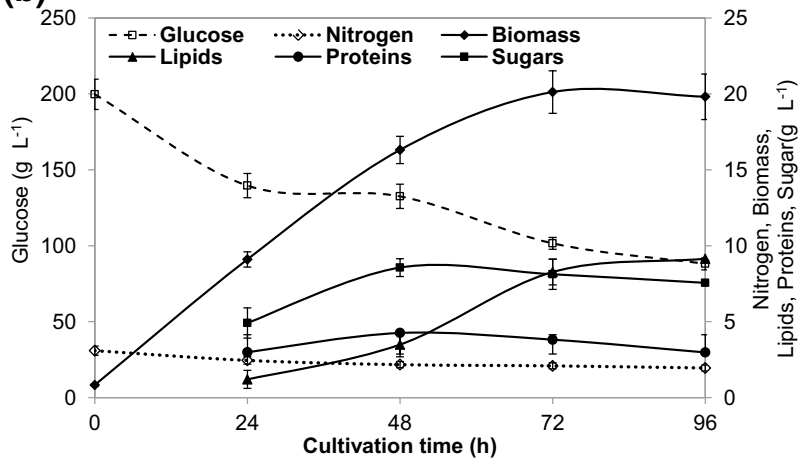

Fig. 2 Kinetics of substrates (glucose and nitrogen), biomass and cellular metabolites: (lipids, protein, and sugars yields) in repeated flask cultures of $R$. glutinis var. rubescens in YP medium containing initial concentrations of glucose 5\% (a) and 20\% (b). Values represent the average of triplicate experiments

glucose concentration resulted in further lipids accumulation, and the highest fat yields was more than $9 \mathrm{~g} \mathrm{~L}^{-1}$. In contrast, the rate of consumption of the carbon source (Fig. 3a) in the DPW medium was lower compare with that in the YP medium, regardless of the initial concentration. Maximum volumetric lipids yields were determined in $72 \mathrm{~h}$ of culture. After that time, this coefficient decreased, while an increase in the volumetric sugar yield was observed. For using the highest concentration of glucose (Fig. 3b), a very significant increase in sugar yield and a smaller increase in volumetric lipids yield were observed after $72 \mathrm{~h}$.

The initial concentration of nitrogen was different (31 $\mathrm{g} \mathrm{L}^{-1}$ of YP media and $15.5 \mathrm{~g} \mathrm{~L}^{-1}$ in the DPW), which simultaneously determined the different initial C:N ratio (Table 2). Influence of the type of culture medium on the total degree of $\mathrm{C}$ and $\mathrm{N}$ utilization are shown in Table 3. The total glucose utilization was slightly higher when using YP substrates. But a significant difference was observed between the medium with the highest initial glucose content. The use of nitrogen has been different. The total degree of nitrogen utilization in the DPW was two times higher than that in the YP medium.
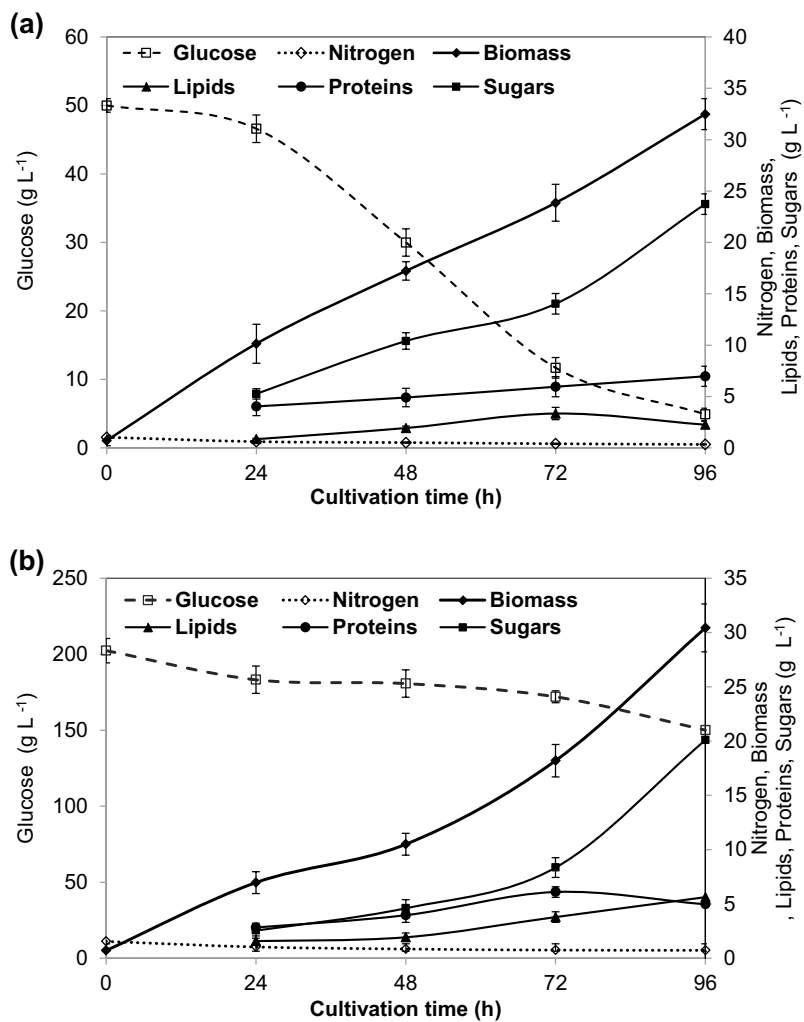

Fig. 3 Kinetics of substrates (glucose and nitrogen), biomass, and cellular metabolites (lipids, protein, and sugars yield) in repeated flask cultures of $R$. glutinis var. rubescens in DPW medium containing initial glucose concentrations of 5\% (a) and 20\% (b). Values represent the average of triplicate experiments

\section{Fatty acids composition and biodiesel characteristic}

The composition of fatty acids is crucial and determines the practical use of yeast's lipids as a source of nutritionally valuable fats or biodiesel. Table 4 shows fatty acids

Table 3 The total degree of utilization (\%) of carbon and nitrogen source

\begin{tabular}{lll}
\hline $\begin{array}{l}\text { Type of culture } \\
\text { medium }\end{array}$ & $\begin{array}{l}\text { Total degree of glucose } \\
\text { utilization } \%\end{array}$ & $\begin{array}{l}\text { Total degree of } \\
\text { nitrogen utiliza- } \\
\text { tion } \%\end{array}$ \\
\hline YP 5\% & $97.20^{\mathrm{d}}$ & $34.19^{\mathrm{a}}$ \\
YP 10\% & $75.40^{\mathrm{c}}$ & $33.66^{\mathrm{a}}$ \\
YP 15\% & $55.46^{\mathrm{b}}$ & $33.87^{\mathrm{a}}$ \\
YP 20\% & $55.80^{\mathrm{b}}$ & $36.89^{\mathrm{a}}$ \\
DPW 5\% & $95.80^{\mathrm{d}}$ & $67.84^{\mathrm{c}}$ \\
DPW 10\% & $71.80^{\mathrm{c}}$ & $65.27^{\mathrm{c}}$ \\
DPW 15\% & $64.60^{\mathrm{b}, \mathrm{c}}$ & $64.63^{\mathrm{c}}$ \\
DPW 20\% & $26.15^{\mathrm{a}}$ & $52.05^{\mathrm{b}}$ \\
\hline
\end{tabular}

Within a column, superscripts $\mathrm{a}, \mathrm{b}$, and $\mathrm{c}$ mean values marked with the same letters do not differ significantly, Tukey's test, $\alpha=0.05$ 
Table 4 The fatty acids range composition after the incubation with the YP and DPW media

\begin{tabular}{|c|c|c|c|}
\hline Fatty acid & Scientific or common name & YP media & DPW media \\
\hline C10:0 & Decanoic acid (capric acid) & $0.2-0.5$ & $0.0-0.5$ \\
\hline C12:0 & Dodecanoic acid (lauric acid) & $0.2-0.7$ & $0.3-4.2$ \\
\hline C14:0 & Tetradecanoic acid (myristic acid) & $0.5-0.8$ & $1.1-2.8$ \\
\hline $\mathrm{C} 16: 0$ & Hexadacanoic acid (palmitic acid) & $19.3-27.0$ & $15.3-17.8$ \\
\hline${ }^{\Delta 9} \mathrm{C} 16: 1$ & cis-7-Hexadecenoic acid (palmitoleic acid) & $1.1-4.0$ & $0.7-4.5$ \\
\hline $\mathrm{C} 17: 0$ & Heptadecanoic acid (margaric acid) & $0.9-1.4$ & $1.0-2.8$ \\
\hline${ }^{\Delta 10} \mathrm{C} 17: 1$ & cis-10-Heptadecenoic acid (cis-10 margaric acid) & $0.5-2.2$ & $1.2-3.3$ \\
\hline C18:0 & Octadecanoic acid (stearic acid) & $9.1-16.0$ & $5.8-7.5$ \\
\hline${ }^{\Delta 9} \mathrm{C} 18: 1$ & cis-9-Octadecenoic acid (oleic acid) & $33.1-43.6$ & $41.0-51.5$ \\
\hline${ }^{\Delta 9,12} \mathrm{C} 18: 2$ & cis-9,12-Octadecadienoic acid (linoleic acid, $\omega$-6) & $1.2-3.2$ & $3.6-5.5$ \\
\hline${ }^{\Delta 9,12,15} \mathrm{C} 18: 3$ & cis-9,12,15-Octadecatrienoic acid ( $\alpha$-linolenic acid) & $0.2-0.8$ & $0.6-1.3$ \\
\hline C20:0 & Icosanoic acid (arachidic acid) & $0.1-0.6$ & $0.1-0.6$ \\
\hline${ }^{\Delta 11} \mathrm{C} 20: 1$ & cis-9-Icosenoic acid (gadoleic acid) & $1.0-1.9$ & $1.2-2.8$ \\
\hline${ }^{\Delta 11,14} \mathrm{C} 20: 2$ & cis-11,14-Eicosadienoic acid, $\omega-6$ & $0.3-1.3$ & $0.7-1.9$ \\
\hline $\mathrm{C} 22: 0$ & Docosanoic acid (behenic acid) & $4.5-14.7$ & $1.9-6.0$ \\
\hline${ }^{\Delta 13,16} \mathrm{C} 22: 2$ & cis-13,16-Docosadienoic acid & $0.0-0.2$ & $0.4-3.0$ \\
\hline $\mathrm{C} 23: 0$ & Tricosanoic acid & $0.6-1.0$ & $0.0-0.4$ \\
\hline \multirow[t]{2}{*}{$\mathrm{C} 24: 0$} & Tetracosanoic acid (lingoceric acid) & $0.5-0.9$ & $0.6-1.2$ \\
\hline & Others & $4.6-6.3$ & $2.9-3.4$ \\
\hline
\end{tabular}

composition range of lipids after incubation with both the media. Oleic acid $\left({ }^{{ }^{9}} \mathrm{C} 18: 1\right)$ and palmitic (C16:0) were the predominant fatty acids regardless of the type of medium and the initial glucose concentration. Stearic (C18:0) and palmitoleic $\left({ }^{\Delta 9} \mathrm{C} 16: 1\right)$ acids were also found in significant quantities in yeast lipids.

The DPW changed the content of certain fatty acids. Compared with YP medium, the biomass lipids were characterized by a higher content of oleic acid $\left({ }^{4} \mathrm{C} 18: 1\right)$, linoleic acid $\left({ }^{\Delta 9,12} \mathrm{C} 18: 2\right)$, and $\alpha$-linolenic acid $\left({ }^{{ }^{99,12,15}} \mathrm{C} 18: 3\right)$, and a lower behenic acid (C22:0)—which increased with the increasing initial glucose concentration. Similarly, an increasing glucose concentration increased palmitoleic $\left({ }^{\Delta 9} \mathrm{C} 16: 1\right)$ and eicosanoic acid $\left({ }^{\Delta 11} \mathrm{C} 20: 1\right)$ and decreased oleic acid $\left({ }^{\Delta 9} \mathrm{C} 18: 1\right)$ contents irrespective of the type of medium. Only in the DPW medium where the glucose concentration increased, palmitic and myristic and $\omega-6$ eicosanoic acid $\left({ }^{\Delta 11,14} \mathrm{C} 20: 2\right)$ contents were higher. In the last day of culture in the DPW medium, a significant increase in the share of saturated fatty acid (SFA) and monounsaturated fatty acids (MUFA) (expressed as \% CDW and $\mathrm{mg} \mathrm{L}^{-1}$ ). A higher proportion of MUFA in the DPW medium was observed. However, in the YP control medium, the cells in the stationary growth phase were characterized by lipids with a high proportion of saturated-palmitic, stearic, and behenic-fatty acids.

Shifts in fatty acids desaturase activity with time may be estimated by calculating the ratios of desaturase product to the substrate [10]. The high C18:1/C18:0 ratios (5.46-15.52) compared with $\mathrm{C} 16: 1 / \mathrm{C} 16: 0$ ratios $(0.05-0.26)$ during incubation with DPW may suggest important $\Delta 9$ desaturase activity that has a better affinity for fatty acids with 18 carbon atoms than for those with 16 carbon atoms. Makri et al. [22] demonstrated a high activity of $\Delta 9$ desaturase during the exponential phase of yeast growth. In this study, high levels of C18:1/C18:0 on the final culturing day were observed in the medium characterizing high initial glucose concentration. This should be explained by the multiplication of cells even after 3 days of incubation, which corresponds to the culture kinetics (Fig. 3).

Biodiesel properties calculated based on the fatty acids composition of the microbial oil producers by $R$. glutinis var. rubescens in YPD and DPW media dependent on initial glucose concentrations are shown in Table 5. The predicted cetane number of the SCO from $R$. glutinis var. rubescens was rather low and the average low calorific value was $37.8 \mathrm{MJ} \mathrm{kg}^{-1}$. Flash points of biodiesel are more than $122{ }^{\circ} \mathrm{C}$. The predicted viscosity of the yeast oil after incubation with the DPW medium was high ( $>5)$.

\section{Discussion}

Analysis of the potato wastewater obtained from the process line after the deproteinization stage indicated containing nitrogen and other elements and can be a source of biogenic elements for yeast growth $[7,11,17]$. Potato wastewater is also a good source of vitamins $\mathrm{B}_{1}, \mathrm{~B}_{2}, \mathrm{~B}_{6}, \mathrm{~B}_{3} / \mathrm{PP}$, and $\mathrm{C}$, which positively affects the growth of yeast [18]. The wastewater was sterilized and centrifuged before preparation of 
Table 5 Biodiesel properties: unsaturation degree (UN), cetane number $(\mathrm{CN})$, length of chain (LC), low caloric value (LCV), flash point (FP), and viscosity $(\mu)$, based on the fatty acids of the microbial oil produced by Rhodotorula glutinis var. rubescens

\begin{tabular}{lllllll}
\hline Medium & $\mathrm{CN}$ & $\mathrm{UD}$ & $\mathrm{LC}$ & $\mathrm{LCV}\left(\mathrm{kJ} \mathrm{kg}^{-1}\right)$ & $\mathrm{FP}\left({ }^{\circ} \mathrm{C}\right)$ & $\mu\left(\mathrm{mm}^{2} \mathrm{~s}^{-1}\right)$ \\
\hline YP 5\% & $58 \pm 7.00$ & $0.51 \pm 0.23$ & $17.54 \pm 0.05$ & $37726.44 \pm 102$ & $183.71 \pm 10.3$ & $5.99 \pm 0.45$ \\
YP 10\% & $52 \pm 8.36$ & $0.58 \pm 0.11$ & $17.75 \pm 0.46$ & $37803.50 \pm 269$ & $190.14 \pm 22.0$ & $6.00 \pm 0.52$ \\
YP 15\% & $49 \pm 2.77$ & $0.61 \pm 0.19$ & $17.97 \pm 0.09$ & $37899.37 \pm 115$ & $197.65 \pm 11.0$ & $6.12 \pm 0.40$ \\
YP 20\% & $48 \pm 1.00$ & $0.48 \pm 0.06$ & $18.15 \pm 0.05$ & $38031.62 \pm 81.0$ & $209.96 \pm 7.80$ & $6.46 \pm 0.08$ \\
DPW 5\% & $50 \pm 7.71$ & $0.81 \pm 0.15$ & $17.62 \pm 0.03$ & $37644.01 \pm 73.0$ & $176.21 \pm 5.70$ & $5.51 \pm 0.26$ \\
DPW 10\% & $51 \pm 3.88$ & $0.61 \pm 0.16$ & $17.81 \pm 0.17$ & $37819.28 \pm 123$ & $191.28 \pm 10.6$ & $5.99 \pm 0.29$ \\
DPW 15\% & $51 \pm 2.98$ & $0.76 \pm 0.04$ & $17.68 \pm 0.09$ & $37700.32 \pm 53.0$ & $180.53 \pm 5.90$ & $5.64 \pm 0.17$ \\
DPW 20\% & $49 \pm 4.21$ & $0.72 \pm 0.05$ & $17.75 \pm 0.04$ & $37700.32 \pm 95.0$ & $184.32 \pm 5.80$ & $5.82 \pm 0.15$ \\
ASTM D6751 & $>47$ & & & & $>93$ & $1.9-6$ \\
EN 14214 & $>54$ & & & & $>120$ & $3.5-5$ \\
\hline
\end{tabular}

Values represent the average of triplicate experiments \pm standard deviations culture media. Electrophoretic analysis of DPW medium in an earlier study did not confirm the presence of proteins of a weight lower than $250 \mathrm{kDa}$ [11], which is due to the centrifugation of the waste prior to the preparation of the medium. Deproteinated potato wastewater contained only $0.44 \%$ of directly reducing sugars what could not result in a high biomass yield. Therefore, DPW was supplemented with additional carbon source to preferably balance its availability in media from this waste. In the present study, glucose was used for this purpose. The process of lipids accumulation by yeast is induced by an initial $C: N$ ratio of higher than 20 or 70 [27] or even higher than 150 [2]. For this reason, various glucose concentrations $(5,10,15$ and $20 \%)$ were used.

The ability of Rhodotorula glutinis var. rubescens to produce such very high biomass quantities (30-40 $\mathrm{g} \mathrm{L}^{-1}$ ) cultivating in DPW were observed. The yield of the biomass obtained after DPW culture was substantially higher than after YPD. The components of the DPW medium significantly promoted yeast cell growth. There was the absence of any inhibitory substances also.

The content of main intracellular components of biomass were dependent on the medium type. The time of cultivation was an important parameter influencing the contribution of individual components of yeast biomass $R$. glutinis var. rubescens. Therefore, when the purpose of culturing is obtained a high protein content, it should be kept only for $24 \mathrm{~h}$. After this time of incubation, even more than $60 \mathrm{~g}$ of protein (data not shown) were obtained from $100 \mathrm{~g}$ of glucose substrate, which should be considered a very good source of single-cell proteins (SPC). In addition, biomass of Rhodotorula red yeast is rich in carotenoids. Carotenoids exhibit health-promoting activity, antioxidative effect against free radicals and reactive oxygen species, strengthen immune system, and torulene and torularhodin inhibit the growth of some type of cancer. The global market is constantly developing depending on the fact that carotenoids are commonly used in food industry as food pigments, additives to fodders and fish, and also as components of cosmetics [15].
The maximum lipid production in the range $1.3-2.9 \mathrm{~g} \mathrm{~L}^{-1}$ after incubation with paper wastewater, which corresponded to the intracellular lipid contents of $8-15 \% \mathrm{CDW}$, were obtained using various carbon substrates (glucose, xylose, and glycerol influence was detected) [1]. In contrast, the biomass of the R. glutinis strain contained about $9.5 \%$ of lipids on the utilization of waste water after the production of sodium glutamate. Despite such low fat content, the authors succeeded in performing esterification with methanol and obtaining a product meeting the requirements of a biodiesel [37]. After $60 \mathrm{~h}$ of cultivation in a 5-L biofermenter tank with corn starch wastewater, the lipids content amounted to $30 \%$ [36]. Wastewater from potato processing (directly after mechanical peeling) allowed for fast and significant $R$. glutinis CBS20 cell growth until $48 \mathrm{~h}$ of cultivation, reaching a 3.5 higher weight of $0.91 \mathrm{~g} \mathrm{~L}^{-1}$ compared with the initial cell mass. Final lipids content did not exceed 10\% d.w [34].

The final content of the individual intracellular metabolites $R$. glutinis var. rubescens LOCKR13 indicates a better lipid synthesis capability, when the nitrogen source and other compounds are peptone and yeast extract than DPW. The highest content of lipids in biomass was observed after culturing in YP 20\% medium. The DPW allows for high yields of biomass; however, with a lesser share of intracellular fats. Nevertheless high biomass yields achieved during incubation at DPW compensate for the average values of lipids content, which consequently allows higher volume yields from the substrate unit. Still, the use of the test waste as a substrate is valuable from the viewpoint of lipids biosynthesis, as it results in a large biomass yield of "medium rich" oily cells, rather than less "highly rich" oily cells. As the initial glucose concentration increased in the DPW medium, fat content increased, which was followed by a decrease in the content of intracellular sugars and proteins. There was a noticeable high proportion of sugars in biomass cultivating in DPW media, which must affect the lipids content. The high biomass yield entitles of potato wastewater as the base of medium. This study is the starting point for 
use other carbon sources as crude glycerol, whey or starch hydrolysates.

Although the YP 10\% and DPW 5\% medium have a similar initial C:N ratio, the degree of utilization of these elements, the yield of biomass, and lipids content are significantly different. The cause of these differences might be due to the type of nitrogen and other substrate elements. Under low nitrogen oily yeast start accumulating oil as intracellular lipid body. Though high lipid content against cell dry weight is achieved, the initial nitrogen stress produces low biomass quantity, which ultimately gives low quantitative oil yield. Instead after the first day of incubation biomass yields were lower in media containing $20 \%$ of glucose. However, final biomass yield was not different compare to $5 \%$. It suggests the fed batch cultivation should result faster biomass production during exponential growth phase and accelerate the lipids accumulation. The Rhodotorula sp. yeast produces ethanol under high glucose concentration, if there is a nitrogen limitation. An endophytic Rhodotorula mucilaginosa strain was found to be capable of production of ethanol from glucose (84\% of theoretical yield) [6]. It suggests an ethanol determination during yeast cultivation to get a mass balance in further experiments.

According to the literature, the $\mathrm{pH}$ in the range 4.0-7.0 does not significantly affect the lipids content, the fatty acid profile and the protein or carotenoids present in the biomass of $R$. glutinis [16]. A strong and spontaneous alkalization of the environment during the yeast culture in the DPW disturbs the homeostasis of nutrients and affects the expression of genes controlling the glucose uptake and metabolism, which may be a stress factor for the cell. The phenomenon of spontaneous alkalization of the medium prepared based on the DPW was explained in an earlier research [11].

The composition of fatty acids is determines the destiny of use of lipids as a source of nutritionally valuable oils or biodiesel. Lipids extracted from examined yeast strain demonstrated a large share of $\mathrm{C} 18$ acids, among which oleic acid $\left({ }^{\Delta 9} \mathrm{C} 18: 1 \mathrm{C} 18: 1\right)$ was predominant. Oils rich in oleic acid (olive oil) are supposed to present modulatory effects in a wide physiological function influence on health [32].

The possibility of using fat as a raw material in the production of biodiesel depends on the different physicochemical characteristics of the fuel. High cetane number $(\mathrm{CN})$ of the fuel is a primary indicator of the fuel quality, which is related to the ignition delay time and a guaranteed good cold start behavior and a smooth run of the engine. Cetane number of the biodiesel should have a minimum value 54 according to EN 14214 (UE countries) or 47 according to ASTM D6751 (USA). Fuels with low cetane numbers tend to increase gaseous and particulate exhaust emissions [14]. The rather low cetane number of the SCO from $R$. glutinis var. rubescens means that it does not meet the expected European standard, but only the American ASTM D6751 standard. The low calorific value (LCV) is another important parameter of a fuel representing the amount of heat transferred to the chamber during combustion and indicates the available energy in a fuel [9]. The average calorific value of coal is $32-37 \mathrm{MJ} \mathrm{kg}^{-1}$, petrol $46 \mathrm{MJ} \mathrm{kg}^{-1}$ and diesel fuel $43 \mathrm{MJ} \mathrm{kg}^{-1}$ [25] and this study biodiesel $37.8 \mathrm{MJ} \mathrm{kg}^{-1}$. Regardless of the medium and glucose concentration, flash points (FP) of biodiesel are more than $122^{\circ} \mathrm{C}$ (according to EN 14214), which means the yeast oil is safe to store [28]. The high predicted viscosity of the yeast oil after incubation with the DPW medium means that it would meet the expected American standards only. But, it only applies to lipids extracted from the biomass after culturing in the waste medium, which we associate with significant increasing SFA and MUFA contents during the final hours of incubation. The high kinematic viscosity of the biodiesel could affect the atomization of the fuel on injection; therefore, it has an impact on injection and combustion. Factors such a double bond configuration influence the viscosity whereas double bond position affects viscosity less [14]. This result shows the possibility that the methylated esters of lipids from $R$. glutinis var. rubescens yeast cultivated on the DPW can be used as a biodiesel in unmodified diesel engines. However, a biodiesel prediction based on purely empirical formulae and fatty acid compositions (carbon chain length as well as saturation/unsaturation) should not be treated as final. During the real time extraction of lipids from yeast the situation will become more complex, as the fatty acid can be associated with more other compounds.

The high degree of utilization of nitrogen and glucose during yeast incubation significantly reduces COD and $\mathrm{BOD}_{5}$ of the potato wastewater. Using DPW as a medium creates the possibility of valorization of this wastewater toward the production of Rhodotorula glutinis var. rubescens yeast biomass. Earlier reports have shown that the use of the DPW as a valuable nutrient ingredient for Candida utilis ATCC 9950 yeast culture medium has resulted in a significant reduction of the above mentioned indicators [7, 19].

\section{Conclusions}

Deproteinated potato wastewater was successfully investigated as a the primary source of nitrogen and minerals in a culture medium for Rhodotorula glutinis var. rubescens LOCKR13 strains. DPW supplemented with glucose promote the growth and biomass productivity of yeast what creates the possibility of valorization of these wastewater. We demonstrate here the time of cultivation was an important parameter defining the contribution of main cellular metabolites of yeast biomass. It has been confirmed that the strain $R$. glutinis var. rubescens belongs to the oleaginous one and is able to accumulate $46 \%$ cell dry weight of lipids 
in medium containing peptone, yeast extract and glucose (20\%). Moreover, this result shows the possibility that the methylated esters of lipids from yeast biomass bred on the DPW can be used as a biodiesel. After all data analysis, it has to be claim that DPW supplemented with glucose is not a medium that efficiently induces lipogenesis in Rhodotorula glutinis var. rubescens. Nevertheless the high biomass yields achieved during incubation at DPW compensate for the average values of lipids content, which consequently allows efficient volumetric yields. Our research confirmed suitability of $R$. glutinis var. rubescens LOCKR13 strain and new developed medium based on potato wastewater for further applications targeting valuable cellular components including lipids.

\section{Materials and methods}

\section{Strain for microbial oil synthesis}

The yeast strain $R$. glutinis var. rubescens LOCKR13 was obtained from the Centre of Industrial Microorganisms Collection (Institute of Fermentation Technology and Microbiology, Łódź, Poland). The biological material was stored on YPD (containing $20 \mathrm{~g} \mathrm{~L}^{-1}$ peptone, $10 \mathrm{~g} \mathrm{~L}^{-1}$ yeast extract, and $20 \mathrm{~g} \mathrm{~L}^{-1}$ glucose) slants at a temperature of $6-8{ }^{\circ} \mathrm{C}$.

\section{DPW medium}

Potato wastewater was obtained from the processing line of PEPEES S.A. Company (Łomża, Poland) during the potato campaign, after coagulating the proteins using the thermal-acid coagulation technique. The wastewater was sterilized for further evaluation $\left(121^{\circ} \mathrm{C} / 0.1 \mathrm{MPa} / 20 \mathrm{~min}\right)$ using the HiCLAVE HG-80 autoclave (HMC Europe). Total nitrogen content was determined by the Kjeldahl method [13], and the factor 6.25 was used to convert nitrogen per protein. The specific protein content was determined by the Lowry method at $\lambda=750 \mathrm{~nm}$ (UV-1800, Rayleigh) [21]. The content of reducing substances was determined spectrophotometrically $(k=550 \mathrm{~nm})$ with the use of 3,5-dinitrosalicylic acid [24]. The content of the selected elements was determined by inductively coupled plasma atomic emission spectroscopy (ICP-AES). DPW $(2 \mathrm{~mL})$ was mineralized in a mixture of nitric acid $(5 \mathrm{~mL})$ and perchloric acid $(2 \mathrm{~mL})$ using a Buchi Digestion Unit K-435. Then, the digestion mixture was transferred by purging with hydrochloric acid to $25 \mathrm{~mL}$ flasks and filled with deionized water. The content of the selected elements (P, K, Na, Ca, Mg, and $\mathrm{Mn}$ ) in DPW was determined with the help of ICP-AES (Thermo iCAP 6500) following the previous method described [11]. The results were stated in terms of grams of elements adjusted to $1 \mathrm{~L}$ of DPW.
DPW was centrifuged to remove any precipitates $(3200 \times g / 20 \mathrm{~min})$ (Eppendorf 5810 Centrifuge), and then glucose was added with initial concentrations of $5 \%, 10 \%$, $15 \%$, and $20 \%$ to obtain media designated as DPW 5\%, DPW $10 \%$, DPW 15\%, and DPW 20\%. YP media containing yeast extract (1\%), peptone (2\%), and glucose at concentrations of 5\%,10\%,15\%, and 20\%, were designated as YP 5\%, YP $10 \%$, YP $15 \%$, and YP $20 \%$. The initial $\mathrm{pH}$ of all the media was set at 5.6 with $\mathrm{NaOH}$. All the media were sterilized by autoclaving at $121{ }^{\circ} \mathrm{C} / 0.1 \mathrm{MPa} / 20 \mathrm{~min}$, using HiCLAVE HG-80 autoclave (HMC Europe).

\section{Culture conditions}

The inoculating cultures were incubated for $48 \mathrm{~h}$ at $28{ }^{\circ} \mathrm{C}$ on a reciprocating shaker (SM-30 Control, Buechler, Germany) at a frequency of 200 cycles/min. Experimental cultures $\left(100 \mathrm{~cm}^{3}\right.$ total culture volume) were incubated in flasks of $500 \mathrm{~cm}^{3}$ volume. The various media were inoculated by $1 \%(\mathrm{v} / \mathrm{v})$ culture and the cultures were incubated for $96 \mathrm{~h}$ at $28{ }^{\circ} \mathrm{C}$ at a frequency of 200 cycles/min (SM-30 Control, Buechler, Germany) without $\mathrm{pH}$ control. Each culture variant was replicated three times.

\section{Cellular biomass yield and its composition analysis}

The biomass concentration was determined gravimetrically [11]. Protein, sugar, and fat contents were determined in the centrifuged, washed, and dried biomass. The protein content was determined by the Kjeldahl method [13] and the obtained results were converted into percent protein in the biomass using 6.25 conversion rate. The total sugars in the biomass were determined by the DNS method according to Bzducha-Wróbel [8]. For the hydrolysis of cell polysaccharides, $20 \mu \mathrm{L}$ of the sample (three replicates) were weighed into the tubes and $200 \mu \mathrm{L}$ of $72 \% \mathrm{H}_{2} \mathrm{SO}_{4}$ was added. All the tubes were stored at $4{ }^{\circ} \mathrm{C}$ for $24 \mathrm{~h}$. After this time, $1.3 \mathrm{~mL}$ of deionized water was added and the samples were incubated for $4 \mathrm{~h}$ in a water bath at $95{ }^{\circ} \mathrm{C}$. The tubes were cooled to room temperature; $50 \mu \mathrm{L}$ of the hydrolyzed mixture was taken into new tubes, and $50 \mu \mathrm{L}$ of $8 \% \mathrm{NaOH}$ and $900 \mu \mathrm{L}$ of deionized water were added. Further procedures for the determination of reducing sugars in the medium were performed. Considering the dilution, the final result was given in terms of $\mathrm{g}$ glucose $/ 100 \mathrm{~g}$ dry weight.

Determination of fat content in the biomass was performed by the process followed by Bligh and Dyer [5] which was further modified by Zhang et al. [39]. The weights of dry biomass, lipids, proteins, sugars, and consumed glucose were used to calculate biomass/glucose $\left(Y_{\mathrm{X} / \mathrm{S}}\right)$, lipid/glucose $\left(Y_{\mathrm{L} / \mathrm{S}}\right)$, protein/glucose $\left(Y_{\mathrm{P} / \mathrm{S}}\right)$, and sugars/glucose yield $\left(Y_{\mathrm{S} / \mathrm{S}}\right)$ coefficients, expressed in terms of $\mathrm{g} \mathrm{g}^{-1}$. Volumetric lipids efficiency 
was also calculated and the mean quantity of lipids produced by $1 \mathrm{~L}$ of the medium was assessed.

The qualitative analysis of fatty acids was performed by gas chromatography coupled to a flame ionization detector (GC-FID TRACE 1300, Thermo Scientific). The fatty acids contained in the extraction samples were dissolved in $2 \mathrm{~mL}$ of hexane and then converted into methyl esters by methylation with $2 \mathrm{M}$ potassium methoxide solution. Methylation was performed at $37^{\circ} \mathrm{C}$. After $12 \mathrm{~h}$, the hexane layer was collected onto chromatography plates and subjected to chromatographic separation using Rtx-2330 column $(60 \mathrm{~m} \times 0.25 \mathrm{~mm} \times 0.2 \mu \mathrm{m})$. Samples were injected at $250{ }^{\circ} \mathrm{C}$ (1:10 split). The following gradient temperature of the chromatography furnace was used: $50{ }^{\circ} \mathrm{C}$ (for $3 \mathrm{~min}$ ), temperature increase of $3{ }^{\circ} \mathrm{C} / \mathrm{min}$ up to $250{ }^{\circ} \mathrm{C}(5 \mathrm{~min})$. The separation was conducted at a steady flow of helium through a capillary column (flow rate $1.6 \mathrm{~mL} / \mathrm{min}$ ). The flame ionization detector (FID) temperature was $260^{\circ} \mathrm{C}$. The identification of methyl esters was based on the retention times of the standards present in the GLC 461 mixture.

\section{Calculation of biodiesel properties}

The properties of fatty acids methyl esters namely, unsaturation degree (UD), cetane number (CN), length of chain (LC), low caloric value (LCV), flash point (FP), and viscosity $(\mu)$ were theoretically estimated based on the following equations:

$\mathrm{UD}=\left(1 \%_{\mathrm{MU}}+2 \%_{\mathrm{DU}}+3 \%_{\mathrm{TU}}\right) / 100$,

where: $\%_{\mathrm{MU}}$ is the percentage of weight of the monounsaturated methyl esters, $\%_{\mathrm{DU}}$ is the percentage of weight of the di-unsaturated methyl esters, $\%_{\mathrm{TU}}$ is the percentage of weight of the tri-unsaturated methyl esters [28];

$\mathrm{CN}=\sum \mathrm{SX}_{\mathrm{ME}} \mathrm{CN}_{\mathrm{ME}}$

where $\mathrm{X}_{\mathrm{ME}}$ is the weight percentage of each methyl ester, $\mathrm{CN}_{\mathrm{ME}}$ is the cetane number of individual methyl ester [29];

$\mathrm{LC}=R\left(n \mathrm{C}_{n} \mathrm{c}_{n}\right)$,

where $n \mathrm{C}_{n}$ is the number of carbon atoms of each fatty acid, $\mathrm{c}_{n}$ is the percentage of weight of each methyl ester containing this fatty acids [28],

$\mathrm{LCV}=29385.4+486.866 \mathrm{LC}-387.766 \mathrm{UD}\left(\mathrm{kJ} \mathrm{kg}^{-1}\right)$,

and

$$
\begin{aligned}
\mu= & -1.8327+0.209794 \mathrm{LC}+0.738911 \mathrm{UD} \\
& +0.0166791 \mathrm{LC}^{2}-0.16336 \mathrm{LCUD}+0.335547 \mathrm{UD}^{2}\left(\mathrm{~mm}^{2} \mathrm{~s}^{-1}\right) .
\end{aligned}
$$

\section{Statistical analysis}

Each experiment was carried out in triplicate. The statistical significances were evaluated using a one-way analysis of variance (ANOVA) and Tukey's multiple range test
$(P<0.05)$ STATISTICA program (StatSoft Polska Sp. z o.o., Kraków, Poland) V.10.

Acknowledgements The authors acknowledge Maria Stańkowska working at PEPEES S.A. in Łomża (Poland, Mazovia Voivodeship) for the deproteinated potato wastewater and also the anonymous journal referees for their helpful comments.

\section{Compliance with ethical standards}

Conflict of interest The authors declare that they have no conflict of interest.

Compliance with ethics requirements This article does not contain any studies with human participants or animals performed by any of the authors.

OpenAccess This article is distributed under the terms of the Creative Commons Attribution 4.0 International License (http://creativeco mmons.org/licenses/by/4.0/), which permits unrestricted use, distribution, and reproduction in any medium, provided you give appropriate credit to the original author(s) and the source, provide a link to the Creative Commons license, and indicate if changes were made.

\section{References}

1. Amirsadeghi M, Shields-Menard S, Hernandez R (2015) Lipid production by Rhodotorula glutinis from pulp and paper wastewater for biodiesel production. J Sustain Bioen Sys 5:114-125

2. Angerbauer C, Siebenhofer M, Mittelbach M, Guebitz GM (2008) Conversion of sewage sludge into lipids by Lipomyces starkeyi for biodiesel production. Bioresour Technol 99:3051-3056. https:// doi.org/10.1016/j.biortech.2007.06.045

3. Beopoulos A, Nicaud JM (2012) Yeast: a new oil producer? OCL 19:22-28. https://doi.org/10.1051/ocl.2012.0426

4. Bernstein AM, Roizen MF, Martinez L (2014) Purified palmitoleic acid for the reduction of high-sensitivity C-reactive protein and serum lipids: a double-blinded, randomized, placebo controlled study. J Clin Lipodol 8(6):612-617. https://doi.org/10.1016/j. jacl.2014.08.001

5. Bligh EG, Dyer WJ (1959) A rapid method of total lipid extraction and purification. Can J Biochem Physiol 37:911-931

6. Bura R, Vajzovic A, Doty SL (2012) Novel endophytic yeast Rhodotorula mucilaginosa strain PTD3 I: production of xylitol and ethanol. J Ind Microbiol Biotechnol 39(7):1003-1011. https://doi. org/10.1007/s10295-012-1109-x

7. Bzducha-Wróbel A, Błażejak S, Molenda M, Reczek L (2015) Biosynthesis of $\beta(1,3) /(1,6)$-glucans of cell wall of the yeast Candida utilis ATCC 9950 strains in the culture media supplemented with deproteinated potato juice water and glycerol. Eur Food Res Technol 240:1023-1034. https://doi.org/10.1007/s0021 7-014-2406-6

8. Bzducha-Wróbel A, Kieliszek M, Błażejak S (2013) Chemical composition of the cell wall of probiotic and brewer's yeast in response to cultivation medium with glycerol as a carbon source. Eur Food Res Technol 237:489-499. https://doi.org/10.1007/ s00217-013-2016-8

9. Demirbas A (2008) Comparison of transesterification methods for production of biodiesel from vegetable oils and fats. Energy Conv Man 49:125-130. https://doi.org/10.1016/j.encon man.2007.05.002 
10. Fakas S, Makri A, Mavromati M, Tselepi M, Aggelis G (2009) Fatty acid composition in lipid fractions lengthwise the mycelium of Mortierella isabellina and lipid production by solid state fermentation. Bioresour Technol 100:6118-6120 https://doi. org/10.1016/j.biortech.2009.06.015

11. Gientka I, Kieliszek M, Jermacz K, Błażejak S (2017) Identification and characterization of oleaginous yeast isolated from kefir and its ability to accumulate intracellular fats in deproteinated potato wastewater with different carbon sources. BioMed Res Int https://doi.org/10.1155/2017/6061042

12. Gonzalez-Garcia Y, Hernandez R, Zhang G, Escalante FME, Holmes W, French WT (2013) Lipids accumulation in Rhodotorula glutinis and Cryptococcus curvatus growing on distillery wastewater as culture medium. Environ Prog Sustain Energy 32:69-74. https://doi.org/10.1002/ep.10604

13. Kirk PL (1950) Kjeldahl method for total nitrogen. Anal Chem 22(2):354-358. https://doi.org/10.1021/ac60038a038

14. Knothe G (2005) Dependence of biodiesel fuel properties on the structure of fatty acid alkyl esters. Fuel Proc Technol 86:10591070. https://doi.org/10.1016/j.fuproc.2004.11.002

15. Kot AM, Błażejak S, Gientka I, Kieliszek M, Bryś J (2018) Torulene and torularhodin: "new" fungal carotenoids for industry? Microb Cell Fact 17:49. https://doi.org/10.1186/s1293 4-018-0893-z

16. Kot AM, Błażejak S, Kurcz A, Bryś J, Gientka I, Bzducha-Wróbel A, Maliszewska M, Reczek L (2017) Effect of initial pH of medium with potato wastewater and glycerol on protein, lipid and carotenoid biosynthesis by Rhodotorula glutinis. Electron J Biotechnol 27:25-31. https://doi.org/10.1016/j.ejbt.2017.01.007

17. Kot AM, Błażejak S, Kurcz A, Gientka I (2015) Biodegradation of deproteinized potato wastewater and glycerol during cultivation of Rhodotorula glutinis yeast. Electron J Biotechnol 18(6):428-432. https://doi.org/10.1016/j.ejbt.2015.08.006

18. Kowalczewski P, Celka K, Białas W, Lewandowicz G (2012) Antioxidant activity of potato juice. Acta Sci Pol Technol Aliment 11(2):175-181

19. Kurcz A, Błażejak S, Kot AM, Bzducha-Wróbel A, Kieliszek M (2016) Application of industrial wastes for the production of microbial single-cell protein by fodder yeast Candida utilis. Waste Biomass Valor. https://doi.org/10.1007/s12649-016-9782-z

20. Liu Y, Wang Y, Liu H, Zhang J (2015) Enhanced lipid production with undetoxified corncob hydrolysate by Rhodotorula glutinis using a high cell density culture strategy. Bioresour Technol 180:32-39. https://doi.org/10.1016/j.biortech.2014.12.093

21. Lowry OH, Rosebrough NJ, Farr AL, Randall RJ (1951) Protein measurement with the Folin phenol reagent. J Biol Chem 193:265-275

22. Makri A, Fakas S, Aggelis G (2010) Metabolic activities of biotechnological interest in Yarrowia lipolytica grown on glycerol in repeated batch cultures. Bioresour Technol 101(7):2351-2358. https://doi.org/10.1016/j.biortech.2009.11.024

23. Markiewicz M, Przewodowska A, Przewodowski W, Stochła W (2015) Wykorzystanie chromatografii membranowej do odzyskiwania białek aktywnych biologicznie z odpadów przemysłu skrobiowego. An Set Env Protec Rocznik Ochrona Środowiska 17:1699-1714

24. Miller GL (1959) Use of dinitrosalicylic acid reagent for determination of reducing sugar. Anal Chem 31(3):426-428. https://doi. org/10.1021/ac60147a030

25. Oliveira LE, Da Silva MLCP (2013) Comparative study of calorific value of rapeseed, soybean, jatropha curcas and crambe biodiesel. RE\&PQJ 1(11):679-682. https://doi.org/10.24084/repqj 11.411
26. Ortucu S, Yazici A, Taskin M, Cebi K (2016) Evaluation of waste loquat kernels as substrate for lipid production by Rhodotorula glutinis SO28. Waste Biomass Valor. https://doi.org/10.1007/ s12649-016-9615-0

27. Papanikolaou S, Aggelis G (2011) Lipids of oleaginous yeasts. Part II: technology and potential applications. Eur J Lipid Sci Technol 113:1052-1073. https://doi.org/10.1002/ejlt.201100015

28. Pinzi S, Leiva D, Arzamendi G, Gandia LM, Dorado MP (2011) Multiple response optimization of vegetable oils fatty acid composition to improve biodiesel physical properties. Bioresour Technol 102:7280-7288. https://doi.org/10.1016/j.biortech.2011.05.005

29. Ramos MJ, Fernández CM, Casas A, Rodríguez L, Pérez A (2009) Influence of fatty acid composition of raw materials on biodiesel properties. Bioresour Technol 100(1):261-268. https:// doi.org/10.1016/j.biortech.2008.06.039

30. Ratledge C, Cohen Z (2008) Microbial and algal oils: do they have a future for biodiesel or as commodity oils? Lipid Technol 20:155-160. https://doi.org/10.1002/lite.200800044

31. Saenge C, Cherisilp B, Suksaroge T, Bourtoom T (2011) Potential use of oleaginous red yeast Rhodotorula glutinis for the bioconversion of crude glycerol from biodiesel plant to lipids and carotenoids. Process Biochem 46(1):210-218. https://doi.org/10.1016/j. procbio.2010.08.009

32. Sales-Campos H, Souza PR, Peghini BC, da Silva JS, Cardoso CR (2013) An overview of the modulatory effects of oleic acid in health and disease. Mini Rev Med Chem 13(2):201-210. https:// doi.org/10.2174/1389557511313020003

33. Schneider T, Graeff-Hönninger S, French WT, Hernandez R, Claupein W, Holmes WE, Merkt N (2012) Screening of industrial wastewaters as feedstock for the microbial production of oils for biodiesel production and high-quality pigments. J Combust. https ://doi.org/10.1155/2012/153410

34. Schneider T, Graeff-Hönninger S, French WT, Hernandez R, Merkt N, Claupein W, Hetrick M, Pham P (2013) Lipid and carotenoid production by oleaginous red yeast Rhodotorula glutinis cultivated on brewery effluents. Energy 61:34-43. https://doi. org/10.1016/j.energy.2012.12.026

35. Venegas-Calerón M, Sayanova O, Napier JA (2010) An alternative to fish oils: metabolic engineering of oil-seed crops to produce omega-3 long chain polyunsaturated fatty acids. Prog Lipid Res 49:108-119

36. Xue F, Gao B, Zhu Y, Zhang X, Feng W, Tan T (2010) Pilot-scale production of microbial lipid using starch wastewater as raw material. Bioresour Technol 101:6092-6095. https://doi.org/10.1016/j. biortech.2010.01.124

37. Xue F, Zhang X, Luo H, Tan T (2006) A new method for preparing raw material for biodiesel production. Proc Biochem 41:1699-1702

38. Yen HW, Chang JT (2014) Growth of oleaginous Rhodotorula glutinis in an internal-loop airlift bioreactor by using lignocellulosic biomass hydrolysate as the carbon source. J Biosci Bioeng 119:580-584. https://doi.org/10.1016/j.jbiosc.2014.10.001

39. Zhang G, French WT, Hernandez R, Alley E (2011) Effect of furfural and acetic acid on grown and lipid production from glucose and xylose by Rhodotorula glutinis. Biomass Bioeng 35:734-740

Publisher's Note Springer Nature remains neutral with regard to jurisdictional claims in published maps and institutional affiliations. 